\title{
Application of Campylobacter jejuni Phages: Challenges and Perspectives
}

\author{
Leonid Ushanov ${ }^{1}$, Besarion Lasareishvili ${ }^{1}$, Irakli Janashia ${ }^{2}$ and Andreas E. Zautner ${ }^{3, *(D)}$ \\ 1 Institute of Veterinary Medicine, Agricultural University of Georgia, 0159 Tbilisi, Georgia; \\ l.ushanoff@agruni.edu.ge (L.U.); b.lasareishvili@agruni.edu.ge (B.L.) \\ 2 Institute of Entomology, Agricultural University of Georgia, 0159 Tbilisi, Georgia; i.janashia@agruni.edu.ge \\ 3 Institute of Medical Microbiology, University Medical Center Göttingen, 37075 Göttingen, Germany \\ * Correspondence: azautne@gwdg.de; Tel.: +49-(0)551-39-8549
}

Received: 11 January 2020; Accepted: 7 February 2020; Published: 11 February 2020

Simple Summary: Campylobacter jejuni is a zoonotic bacterial pathogen found in abundance, e.g., in raw poultry. C. jejuni is part of the avian gut microbiome, causing no harm to birds. When birds are slaughtered, the bacterium is released from the intestines and contaminates the meat. Cross-contaminated foods processed in parallel to the meat cause diarrhea in humans and in rare cases may cause post-infectious complications like arthritis and paralysis of peripheral nerves. Illnesses caused by C. jejuni have been on the rise in both developed and developing countries. At the same time, C. jejuni has acquired resistance to important antibiotics, which further complicates therapeutic approaches. To decrease the Campylobacter load on chicken carcasses, chemical or thermal treatment can be used. However, this may change the taste or affect the appearance of chicken meat. Alternative treatments include application of probiotics active against $C$. jejuni to live chickens or the use of bacteriophages (viruses killing bacteria) to decrease Campylobacter in the guts of live chickens prior to killing. This article discusses phage-based applications already in use against other bacterial pathogens and specifically highlights the challenges associated with the use of Campylobacter phages, emphasizing the ways to overcome these challenges based on the existing research.

Abstract: Bacteriophages (phages) are the most abundant and diverse biological entities in the
biosphere. Due to the rise of multi-drug resistant bacterial strains during the past decade, phages are
currently experiencing a renewed interest. Bacteriophages and their derivatives are being actively
researched for their potential in the medical and biotechnology fields. Phage applications targeting
pathogenic food-borne bacteria are currently being utilized for decontamination and therapy of
live farm animals and as a biocontrol measure at the post-harvest level. For this indication, the
United States Food and Drug Administration (FDA) has approved several phage products targeting
Listeria sp., Salmonella sp. and Escherichia coli. Phage-based applications against Campylobacter
jejuni could potentially be used in ways similar to those against Salmonella sp. and Listeria sp.;
however, only very few Campylobacter phage products have been approved anywhere to date. The
research on Campylobacter phages conducted thus far indicates that highly diverse subpopulations of
C. jejuni as well as phage isolation and enrichment procedures influence the specificity and efficacy of
Campylobacter phages. This review paper emphasizes conclusions from previous findings instrumental
in facilitating isolation of Campylobacter phages and improving specificity and efficacy of the isolates.

Keywords: C. jejuni; bacteriophage; phage-based applications; phage therapy; Campylobacter phages 


\section{Significance of Campylobacter jejuni as a Pathogen}

Campylobacter jejuni is a causative agent of bacterial enteritis in humans with serious consequences for children, the elderly and the immunocompromised [1-3]. One of the rare sequelae associated with C. jejuni is Guillain-Barré syndrome (GBS), manifested as demyelination of the peripheral nerves due to autoimmune reaction and paralysis $[4,5]$. About $34 \%-49 \%(\approx 42 \%)$ of GBS cases are likely to be associated with prior Campylobacter infection [6]. Further post-campylobacteriosis sequelae are reactive arthritis, Erythema nodosum, and inflammatory bowel disease [6,7].

The avian reservoir is the predominant source of $C$. jejuni infections, which have been strongly linked to contaminated retail chicken by numerous studies [8,9]. As a commensal organism with high prevalence $\left(10^{9} \mathrm{CFU} / \mathrm{g}\right)$ in chicken ceca, C. jejuni easily contaminates carcasses of slaughtered birds [10]. Davis and colleagues demonstrated experimentally that Campylobacter survives well on both chicken skin and meat at refrigerated temperatures [11].

Cases of $C$. jejuni-associated food poisoning have been rising worldwide. Studies from Brazil, Great Britain, Canada, Italy, Korea, Australia and Japan report contamination rates ranging from 20\% to $80 \%$ [12-15]. According to the European Food Safety Authority (EFSA), Campylobacter continues to be the most commonly reported human gastrointestinal bacterial pathogen in the European Union (EU) since 2005 [16]. C. jejuni infections occurring each year cause close to 350,000 cases of disability and cost 2.4 billion Euros yearly [17]. There were 246,571 confirmed cases of Campylobacteriosis reported in the EU in 2018 [18].

Currently, there is no single effective intervention method for reduction of bird colonization by C. jejuni. Biosecurity measures only achieve partial clearance [19]. This was effectively demonstrated by a study conducted in central Italy where Campylobacter isolates were obtained, both by cloacal swabs and at the post-harvest stage, from farm chicken flocks kept under good sanitary practices [20]. Colonization of broiler chicks by $C$. jejuni takes place within the first three weeks after hatching, and, since Campylobacter colonization is not associated with signs of disease in chickens, horizontal spread of the pathogen usually remains unnoticed $[9,21]$. Combination of strict biosecurity, good manufacturing practice (GMP), hazard analysis and critical control points (HACCP) attempts can alleviate contamination levels but do not lead to a complete elimination of the bacteria. It is difficult to quantify the effectiveness of individual measures because they are dependent on very many interrelated local factors [17]. Additionally, there is no vaccination available against $C$. jejuni due to serological diversity of the pathogen and the short lifespan of broilers [19]. The estimated public benefits in terms of a higher reduction of the disease burden of campylobacteriosis and its sequelae are greater if efforts are made towards controlling C. jejuni during the primary production stage [17].

To control C. jejuni, scientists have proposed several methods based on either supplementing chicken feed with probiotic bacteria capable of inhibiting C. jejuni and/or administering Campylobacter-specific phages to chickens [22-24]. Campylobacter phages are natural "predators" that could potentially be able to bring $C$. jejuni under control. Phages are already being used to control other food-borne pathogens, such as Salmonella spec. and Listeria monocytogenes $[25,26]$. However, despite their historical use in typing Campylobacter spec., there are limited number of reports about application of Campylobacter phages for therapeutic purposes $[27,28]$.

The goal of this review is to analyze the results shown by research using phage-based applications targeting C. jejuni and summarize the scientific and regulatory experience from similar phage products against other food-borne pathogens.

\section{Classification of $C$. jejuni Phages and Receptor Specificity}

Phage typing has been used extensively for epidemiology studies of $C$. jejuni and Campylobacter coli [29]. The number of $C$. jejuni bacteriophages reported to date exceeds 170 and the majority of these phages exhibit a narrow host range [13]. Most Campylobacter phages are lytic, i.e., virulent or able to lyse the host bacteria upon infection and are thus preferred due to their immediate effect [30]. Lysogenic or temperate phages are generally avoided for their ability to integrate into a bacterial 
genome and transduce virulence genes from strain to strain [31-34]. There are several ways to classify phages. Generally, phage classification schemes are based on their morphology, genetic makeup (e.g., DNA vs. RNA) or genome size (Table 1) [35]. Morphologically, the majority of $C$. jejuni phages are categorized into the family Myoviridae (Bradley's morphotype A1, contractile tail), while some have been designated as Siphoviridae (Bradley's morphotype B1, non-contractile tail) [36].

Table 1. Classification of lytic Campylobacter Phages.

\begin{tabular}{cccc}
\hline Group & Phage Size in kbp & Receptor Specificity & Alternative Classification \\
\hline I & $320-425$ & mostly flagellotropic & - \\
II & $175-183$ & mostly flagellotropic & "CP220-like viruses" \\
III & $131-135$ & mostly CPS-specific & "CP8-unalike viruses" \\
\hline
\end{tabular}

Lytic Campylobacter phages are divided into three groups according to the size of their genome: group I contains relatively rare phages with large genomes (approx. 320-425 kbp), while groups II and III include most Campylobacter phages isolated and characterized to date [37]. These are all distantly related to T4 bacteriophages and have smaller genomes: 175 to $183 \mathrm{kbp}$ (group II) and 131 to $135 \mathrm{kbp}$ (group III). Group II and III Campylophages exhibit resistance to many restriction endonucleases. These phages are characterized with great similarities within each group but differences between the groups $[37,38]$. Group II Campylophages are often specific to both C. jejuni and C. coli, while group III phages demonstrate specificity exclusively to C. jejuni and have stronger lytic activity [37].

The latest phage classification scheme, which is based on whole genome sequencing and protein homology, puts group II and III phages into the Eucampyvirinae sub-family of myoviridae as "CP220-like viruses" and "CP8-unalike viruses"|"CP8 virus" [37-39]. Sørensen and colleagues showed, with some exceptions, the connection between receptor dependency and grouping of $C$. jejuni phages. For example, the majority of group III phages use capsular polysaccharide (CPS) receptors, while group II phages target mostly flagellar receptors [27,40].

\section{Phage Applications Targeting Food-Borne Pathogens}

The Earth's biosphere is estimated to contain approximately $10^{32}$ phage particles, exceeding the number of prokaryotic organisms by 10-fold [33,41,42]. Bacteriophages differ in size and shape, and are characterized with incredible genome mosaicity resulting from different environmental pressures, including the adaptation to continuous bacterial resistance [43]. At the time of writing this article, only 8852 complete genomic sequences have been listed in the NCBI database of phage genomes. Thus, numerous novel phage genes, potentially leading to development of new phage-based drugs, are yet to be discovered and studied.

Bacteriophages were successfully used for human therapy almost immediately after their discovery in the beginning of the 20th century [41]. After the triumph of penicillin in 1940s, phage use gradually dwindled in the West, but continued in Georgia (the former USSR) and Poland [44]. The Eliava Institute of Bacteriophage, Microbiology and Virology founded by George Eliava and d'Herelle in Tbilisi in the 1930s still continues its work and has accumulated extensive experience in phage work and phage therapy over the decades. The advent of the era of multi-drug resistant bacteria has rekindled the interest in bacteriophages due to several major advantages of phages over antibiotics. First, bacteriophages are effective regardless of the susceptibility of their host bacteria to antibiotics, i.e., antibiotic-resistant bacterial strains are affected in the same way and with the same effectiveness as non-resistant strains. Second, phages are ubiquitous and relatively easy to isolate. Third, their narrow specificity is instrumental in avoiding the disruption of the entire microbiome in the treatment subject [45]. The fourth advantage is that new, mutant, phages may be developed in a matter of days [46]. Phage-based applications can be used as an alternative to antibiotics in live animals, in situ on processed meat and other foods, and for decontamination of surfaces and equipment in food processing to ensure that no multi-drug resistant bacterial strains selected as a result of antibiotic-based 
evolutionary pressure are released into the wastewater and thus into the environment [25]. Thus, bacteriophage application is manifold and covers different stages of primary (live animals) and secondary (harvested meats) production in animal farm settings. Having no associated toxicity, phage treatments can be complexed with other methods, such as probiotic supplements, aimed at reduction of C. jejuni $[1,4,45]$.

Humans have been continuously exposed to phages via drinking water and fresh foods without any adverse reaction ever recorded [24]. In fact, phages have been isolated from human saliva and intestines [47]. A gram of human feces contains approximately $10^{8}-10^{9}$ virus-like particles comprised mostly of DNA phages $[48,49]$. Based on the evaluation of experts qualified by scientific training and experience, the United States Food and Drug Administration (FDA) recognized phages and phage derivatives as generally regarded as safe (GRAS) through the 1958 Food Additives Amendment to the Federal Food, Drug, and Cosmetic Act [50,51]. A phage manufacturer, however, has to provide proof to the FDA in the form of a GRAS notification indicating the intended use [26]. For example, the GRAS notification for ShigaShield ${ }^{\mathrm{TM}}$ — a phage product developed by Intralytix against Shigella_-specifically states that the GRAS status has been determined "through scientific procedures" [52].

Although most phages are harmless to human health and environment, not all phages are safe, as some lysogenic phages can actually carry and transduce virulence genes. For example, E. coli O157:H7 and Streptococcus pyogenes owe their virulence to the acquisition of phage virulence genes into their genomes [33]. To avoid "phage lysogenic conversion", i.e., changing the properties of specific bacteria, lytic phages must be used, as they immediately lyse the host and do not integrate into the bacterial host genome. For assuring the safety of phage preparations used in animal and human therapy, the latest achievements in sequencing technology are utilized. Bioinformatics methods can rapidly predict undesirable phage properties. The GRAS designation and the FDA approval of phages P100 and LMP-102 were specifically based on this approach following phage sequencing.

Advances in phage research have increased the interest in their possible use as biocontrol agents to preserve or decontaminate food products and, thus, prolong their shelf life while preventing frequent disease outbreaks. According to the US CDC, 841 foodborne disease outbreaks were reported by 50 states, Washington, D.C., and Puerto Rico, resulting in 14,481 illnesses, 827 hospitalizations, 20 deaths, and 14 food recalls in 2017 [53]. The major foodborne bacterial pathogens most frequently associated with lethal outcomes are L. monocytogenes, S. enterica and E. coli (e.g., E. coli O157:H7), followed by C. jejuni $[26,54]$. Naturally, these food-borne pathogens became the focus of the first phage-based applications developed. In dairy production, for example, S. enterica contamination can occur at virtually any stage and phages can be used to reduce the shedding of Salmonella in farm animals, as a food additive in post-harvest food products, and as biocontrol agents in food processing to control the pathogen [25]. Phage therapy against Salmonella has been successful in broiler production and significantly reduced the pathogen in the ceca of broilers [25].

The general recognition of phage applications as GRAS also prepared the ground for regulatory clearance of several phage-based biocontrol products targeting L. monocytogenes, S. enterica and E. coli. The first such product, ListShield ${ }^{\mathrm{TM}}$ (LMP-102) from Intralytix targeting L. monocytogenes "ready to eat" (RTE) foods, was approved by the US FDA in 2006. A similar biocontrol agent against L. monocytogenes, Listex P100, got the FDA approval for the use in meat, cheese and other foods, including fish, shellfish, fresh fruits and vegetables. Thereupon ListShield ${ }^{\mathrm{TM}}$ was approved in Canada and Israel, while Listex has been approved in Switzerland for use in cheesemaking. Approvals for further phage applications followed: in 2007, the FDA approved a product from Omnilytics for decontamination of live animals from E. coli and Salmonella. Within the same year, the FDA followed up with the approval of new phage applications, including the "Finalyze" spray against E. coli O157:H7 in cattle (Elanco Food Solutions) and "Armament" against Salmonella in poultry. Another phage application from Intralytix-EcoShield, 95-100\% effective against E. coli O157:H7, received the FDA's regulatory approval in 2011 for use on red meats prior to grinding [30]. 
Up to the present time, the FDA's GRAS inventory includes phage applications against Shiga-like toxin-producing E. coli, L. monocytogenes, Salmonella and Shigella. None of the listed products target Campylobacter spp., although Intralytix and Micreos have publicly expressed their interest in pursuing the development of such applications [24].

To date, there are only very few patents on phage products relating to their use for Campylobacter germ load reduction in poultry flocks or on processed meat.

Instead of a complete bacteriophage, Fischetti and colleagues patented a process that uses a bacteriophage-derived lysis enzyme for bacterial decontamination of food products [55]. This bacteriophage-derived lysis enzyme can be increased in its effectiveness of bacteriolysis by modification, e.g., by construction of chimeric lytic enzymes, shuffled lytic enzymes or by additional holin proteins. This patent also includes Campylobacter spp. in the list of potential target organisms. However, a specific bacteriophage-derived lysis enzyme was not named in the 2002 patent [56]. In the 2004 version, the bacteriophage-derived lysis enzyme PaI with activity against Streptococcus pneumoniae and other streptococci of the Viridans group were also listed [55].

Based on their in vivo study, Connerton patented the application of the bacteriophages CP8 and CP34 [2] to reduce Campylobacter spp. in the intestine of birds [57] (for further details see Section 4.1, study II and III, as well as Table 2).

Burnett and coworkers patented a procedure to reduce or to prevent bacterial contamination of any type of food product using bacteriophages [58]. The bacteriophages are to be administered in a specific embodiment, which may contain a buffer, surfactant, adjuvants and enhancers to prevent degradation of the bacteriophage and even to enhance its performance as an antibacterial agent. Application of the bacteriophages can also be done on non-food surfaces or water systems. Besides the shown example, L. monocytogenes, Campylobacter spp. and other bacteria are listed as possible target organisms for this procedure.

The patent of Ter Haar and Hanna complements the application of bacteriophages to food by a rubbing process using a vibratory conveyor to distribute the bacteriophage more efficiently on the food surface [59].

The European Food Safety Agency (EFSA) approached the usage of phages as biocontrol agents rather carefully and issued three scientific opinions in 2009, 2012 and 2016. While the 2009 opinion focused on the nature of bacteriophages and their potential use for decontamination of foods, the 2012 opinion was a response to Micreos' application for the approval of LISTEX ${ }^{\mathrm{TM}}$ P100 to reduce L. monocytogenes [60]. This statement addressed safety and efficacy issues of the phage product, but concluded that the product was safe, although the agency had several concerns, specifically on (i) the absence of industrial scale studies, (ii) the limited number of phages used, and (iii) the lack of evidence of significant pathogen reduction. The 2016 opinion finally recognized the safety and efficacy of LISTEX $^{\mathrm{TM}} \mathrm{P} 100$ for the use on meat, poultry, fish, shellfish and dairy products at up to $1 \times 10^{9} \mathrm{PFU}$ [60]. 
Table 2. Studies of C. jejuni-specific phages listed by year.

\begin{tabular}{|c|c|c|c|c|c|}
\hline Reference & $\begin{array}{l}\text { Kind of } \\
\text { Study }\end{array}$ & $\begin{array}{l}\text { Phage } \\
\text { Group }\end{array}$ & $\begin{array}{l}\text { Phage } \\
\text { Origin }\end{array}$ & $\begin{array}{c}\text { C. jejuni } \\
\text { Strain Used }\end{array}$ & Results \\
\hline $\begin{array}{l}\text { Atterbury et al., } \\
2003\end{array}$ & in situ & $\begin{array}{l}\Phi 2(\text { NCTC 12674) } \\
\text { group III }\end{array}$ & NCTC & $\begin{array}{c}\text { C. jejuni NCTC } 12662 \\
\text { (PT 14) }\end{array}$ & $\begin{array}{l}\text { Sections of chicken skin, inoculated with different } \\
\text { concentrations of } C \text {. jejuni and bacteriophages, were kept } \\
\text { at } 4{ }^{\circ} \mathrm{C} \text { and } 20^{\circ} \mathrm{C} \text {. At maximum phage concentration }\left(10^{7}\right) \\
\text { there was } 1.1-1.3 \log _{10} \text { level reduction of } C \text {. jejuni in } 4{ }^{\circ} \mathrm{C} \\
\text { treatment setup and } 2.3-2.5 \log _{10} \text { reduction in } 20^{\circ} \mathrm{C} \\
\text { treatment setup compared to the controls. }\end{array}$ \\
\hline $\begin{array}{l}\text { Goode et al., } \\
2003\end{array}$ & in situ & NCTC 12673, group III & NCTC & $\mathrm{C} 222$ & $\begin{array}{c}1 \log _{10} \text { level reduction observed on chicken skins treated } \\
\text { with the phage at the concentration of } 10^{6} \mathrm{PFU} / \mathrm{cm}^{2} \\
\text { compared to the untreated controls. }\end{array}$ \\
\hline $\begin{array}{l}\text { Wagenaar et al., } \\
2005\end{array}$ & in vivo & $\begin{array}{l}\text { NCTC 12669, Group III } \\
\text { NCTC 12671, Group III }\end{array}$ & NCTC & C356 & $\begin{array}{l}\text { After the initial } 3 \log _{10} \text { levels reduction CFU counts of } \\
\text { C. jejuni increased again within } 5 \text { days and plateaued at } 1 \\
\qquad \log _{10} \text { level lower than control. }\end{array}$ \\
\hline $\begin{array}{l}\text { Loc Carrillo } \\
\text { et al., } 2005\end{array}$ & in vivo & $\begin{array}{l}\text { CP8, Group III } \\
\text { CP34, Group III }\end{array}$ & Retail Chicken & HPC5 GIIC8 & $\begin{array}{l}0.5-5 \log _{10} \text { levels reduction depending on the intestinal } \\
\text { site and phage-host combination. The study } \\
\text { demonstrated that the greatest reduction was achievable } \\
\text { within } 24-48 \text { h. Substantial differences were identified } \\
\text { between in vitro and in vivo results. }\end{array}$ \\
\hline $\begin{array}{l}\text { Bigwood et al., } \\
2008\end{array}$ & in situ & $\begin{array}{c}\text { Cj6 } \\
\text { Group not specified }\end{array}$ & Chicken feces & Chicken isolate & $\begin{array}{c}\text { Cooked and raw beef samples inoculated with } C \text {. jejuni } \\
\text { were treated with bacteriophage and stored at } 5^{\circ} \mathrm{C} \text { and } \\
24^{\circ} \mathrm{C} \text {. The maximum }\left(2 \log _{10} \text { levels }\right) \text { reduction was } \\
\text { achieved in samples that were treated with high densities } \\
\text { of } C \text {. jejuni and high M.O.I. of the phage at both storage } \\
\text { temperatures. }\end{array}$ \\
\hline $\begin{array}{l}\text { Carvahlo et al., } \\
2010\end{array}$ & in vivo & $\begin{array}{l}\text { PhiCcoIBB35, Group II } \\
\text { PhiCcoIBB37, Group II } \\
\text { PhiCcoIBB12, Group II }\end{array}$ & $\begin{array}{l}\text { Free Range } \\
\text { Chickens }\end{array}$ & $2140 \mathrm{CD} 1$ & $\begin{array}{l}\text { Approx. } 2 \log _{10} \text { levels reduction achieved using the } \\
\text { cocktail consisting on the three phages. Phage delivery } \\
\text { with food was more effective than by oral gavage. }\end{array}$ \\
\hline
\end{tabular}


Table 2. Cont

\begin{tabular}{|c|c|c|c|c|c|}
\hline Reference & $\begin{array}{l}\text { Kind of } \\
\text { Study }\end{array}$ & $\begin{array}{l}\text { Phage } \\
\text { Group }\end{array}$ & $\begin{array}{l}\text { Phage } \\
\text { Origin }\end{array}$ & $\begin{array}{c}\text { C. jejuni } \\
\text { Strain Used }\end{array}$ & Results \\
\hline $\begin{array}{l}\text { Orquera et al., } \\
2012\end{array}$ & in situ & $\begin{array}{l}\text { NCTC 12684, group II } \\
\text { CP81, group III }\end{array}$ & NCTC & NCTC 11168 & $\begin{array}{l}\text { No reduction observed at } 4{ }^{\circ} \mathrm{C} \text { in situ on meat or in vitro. } \\
1 \log _{10} \text { reduction was observed in vitro at } 37^{\circ} \mathrm{C} \text {. }\end{array}$ \\
\hline Kittler et al., 2013 & in vivo & $\begin{array}{c}\text { NCTC } 12672 \text { NCTC } 12673 \\
\text { NCTC } 12674 \text { NCTC } 12678 \\
\text { All group III phages }\end{array}$ & NCTC & $\begin{array}{c}\text { NCTC } 12661 \\
\text { NCTC } 12664 \text { NCTC } \\
12660\end{array}$ & $\begin{array}{c}\text { Phage cocktail was administered to birds via } \\
\text { drinking water. } \\
\text { Group I: } 3.2 \log _{10} \text { CFU/g lower C. jejuni counts than in the } \\
\text { control until slaughter. } \\
\text { Group II: No significant reduction } \\
\text { Group III: No reduction }\end{array}$ \\
\hline $\begin{array}{l}\text { Firlieyanti et al., } \\
2016\end{array}$ & in situ & $\begin{array}{l}\Phi 3, \text { group II } \\
\Phi 15, \text { group II }\end{array}$ & $\begin{array}{l}\text { Chicken liver } \\
\text { isolates }\end{array}$ & Chicken liver isolates & $\begin{array}{l}\text { Modest reduction } 0.2 \log _{10} \text { level (low } \mathrm{C} \text {. jejuni } \\
\text { inocula) }-0.8 \log _{10} \text { (high C. jejuni inocula) at } 4{ }^{\circ} \mathrm{C} \text {. }\end{array}$ \\
\hline $\begin{array}{l}\text { Zampara et al., } \\
2017\end{array}$ & in situ & $\begin{array}{c}\text { Group II and Group III } \\
\text { phages identified } \\
\text { previously. }\end{array}$ & $\begin{array}{l}\text { Free range chicken } \\
\text { isolates }\end{array}$ & $\begin{array}{l}\text { NCTC } 12662 \\
\text { RM } 1221\end{array}$ & $\begin{array}{l}\text { The study concluded that CPS phages bound more tightly } \\
\text { to C. jejuni compared to flagellotropic phages and, } \\
\text { therefore, were more efficient at reducing the pathogen at } \\
\text { low temperatures. It was also observed that efficiency of } \\
\text { phage cocktails at reducing C. jejuni was higher than that } \\
\text { of single phages. }\end{array}$ \\
\hline
\end{tabular}




\section{Studies Reveal Variable Specificity and Efficacy of $C$. jejuni Phages}

Studies from different countries resulted in $0.2-3 \log _{10}$ levels of reduction of $C$. jejuni post phage treatment depending on the phage(s), the host strain used, and the method of application. The efficacy data from these studies indicate that understanding phage-host interactions is an important prerequisite to discovering the underlying mechanisms of phage specificity [27]. Studies of Campylobacter-phages are listed below in a chronological order.

\subsection{In Vivo Testing}

In 2005, Wagenaar et al. (study I) tested monophages and two-phage applications against $C$. jejuni in young broilers for preventive and therapeutic purposes. By day 5 , the bacterial CFU counts were up again after initial $3 \log _{10}$ level reduction and plateaued at $1 \log _{10}$ level below the control group. The same was observed with the preventive group following delayed colonization of birds by one week. The efficacy of a polyphage application was comparable to that of individual phages used in vitro. This study also demonstrated that polyphages could slow or prevent development of phage-resistant mutants [61].

Similarly, Loc Carrillo and colleagues (study II) used two Campylobacter phages (CP8 and CP34) in 25-day old broilers applied orally in combination with an antacid. Phage CP8 was active against one tested C. jejuni strain (GIIC8), but not against the other tested C. jejuni strain (HPC5), despite its in vitro susceptibility to the same phage. In contrast, phage $\mathrm{CP} 34$ reduced both $C$. jejuni test strains HPC 5 and GIIC 8 and maintained the reduction for 5 days. However, $72 \mathrm{~h}$ post treatment counts began to increase indicating that in vitro efficacy may be drastically different from the in vivo results [2].

El-Shibiny et al. (study III) applied the same phages (CP8 and CP34) to birds pre-colonized with a wild type C. coli isolate. In this study, another phage, CP220, was also tested in chicks pre-infected at 20 days old with $C$. jejuni strain HPC5. The most important finding of this study was that only high doses of phages ( $\left.10^{9} \mathrm{PFU}\right)$ were able to reduce cecal counts of $C$. coli by $1-2 \log _{10}$ levels within $48 \mathrm{~h}$ and a reduction of $2.1 \log _{10}$ levels of $C$. jejuni HPC 5 could be obtained $24 \mathrm{~h}$ post phage (CP220) administration [62].

Carvalho and colleagues (study IV) also tested a two-phage cocktail (with different lytic spectra) in birds that were colonized by C. jejuni and C. coli. Better results were produced when phages were given to chickens with feed, compared to oral gavage. However, $6 \%$ of the Campylobacter isolates were resistant upon passage through the bird guts [63].

In contrast, Kittler and coworkers (study V) tested a phage cocktail of four group III phages in three commercial broiler farms (in one farm, penicillin was applied over 3 days in advance). Each setup included an experimental group and a control group. One of the experimental groups showed significant reduction of $C$. jejuni counts below the detection limit on day 1 and still over $3 \log _{10}$ levels on the day of slaughter, demonstrating that maximum reduction was achievable $1-4$ days prior to slaughter [64]. The fact that sometimes genotypically identical C. jejuni strains within flocks exhibited different phage susceptibility profiles and varying biotypes was an important observation linking the lack of efficacy of phage applications with genotypic variability of $C$. jejuni isolates.

All five studies were similar in their goal to determine the efficacy of phages, isolated from the environment of commercial broiler farms or obtained from bio banks, in reduction of $C$. jejuni and/or C. coli in artificially (studies I-IV) and naturally (study V) infected broilers. However, fundamentally different approaches could be observed from study to study. First, a good colonizing strain of $C$. jejuni and phages that were previously characterized [36] were used in study I. Because neither the bacterial strain, nor the phages were naturally isolated from local chicken meat or excreta, this model cannot be considered as suitable for wider applications of phages for preventive or therapeutic purposes in farms. Still, this was also the first in vivo study to demonstrate that application of a high dose $\left(10^{11} \mathrm{PFU} / \mathrm{mL}\right)$ of phages to live chickens did not lead to any signs of pathology and resulted in considerable reduction of the host strain $24 \mathrm{~h}$ post application. Phage 71 (a group III lytic phage), which was used in this study, was able to achieve $1 \log _{10}$ level reduction that was maintained within the experimental flock over 
30 days and up to $3 \log _{10}$ levels reduction of C. jejuni C356 in the following $24 \mathrm{~h}$. Another important observation made in this study was that phage 69 , which was less potent and belonged to the same group (group III) of phages, boosted the potency of phage 71, when administered together. The long-term effect of applying the two phages together was $1.5 \log _{10}$ level reduction of the host bacteria compared with $1 \log _{10}$ level when phage 71 was used alone.

Studies II and III tested the same two (CP8 and CP34) phages separately, as well as in a cocktail, against C. jejuni and C. coli, respectively. Additionally, study III also tested a group II phage CP220 against $C$. jejuni and demonstrated the immediate efficacy of a high dose of phages. The benefit of application of phages as a cocktail had already been observed in study I. Therefore, the subsequent studies (III and IV) started administering phages to the chicks in this manner. The major drawback of most studies (I, III and V) was to use phages obtained elsewhere. Local isolates were only used in studies II and IV. These studies used phage isolates from farms around the UK (study II) and free-range chickens (study IV, although without indicating the precise geographical origin, which, presumably, was Portugal). Additionally, study V used strain NCTC 12662 to test the efficacy of phages, while evidence that the three experimental sites were infected with different biotypes of C. jejuni probably already existed. In our opinion, it would be better to use C. jejuni isolates from each respective group in this study (V), rather than strain NCTC 12662.

Fundamental differences were observed in the method of phage selection in two out of five studies. For phage selection Study II used only C. jejuni (host derived isolates from the same sample or the laboratory strain NCTC 12662), while study IV utilized both C. jejuni and C. coli. This turned out to be beneficial for study IV and resulted in selection for phages that were active against both C. coli and C. jejuni exhibiting synergistic efficacy. In contrast, in study II exclusively, CP8-like, i.e., CPS-specific, phages were selected. Another drawback of study II was to use only oral gavage as the route of administration, which seems impractical in large-scale operations, should phage therapy ever be approved for broiler farm use. Oral gavage in study IV was compared with mixing the phage cocktail in the chicken feed, which proved to be more effective. Although it is hard to estimate how the chicken feed contributed to better stability of phage preparations, the results showed that this route of administration led to more sustainable reduction of Campylobacter. However, this effect could also be achieved due to the use of specifically different phages (group II versus group III). In study V, drinking water was used as the means of phage delivery, which certainly is more practical than oral gavage in large-scale operations. However, in the course of the study, no stability experiments were conducted to demonstrate survival of phages in drinking water. Study II, for example, conducted such stability experiments before mixing the phages with calcium carbonate.

In terms of phage resistance, the data from the five studies also differ. For example, studies II and III identified resistance occurring at a rate $<4 \%$ and $2 \%$, respectively. In contrast, $6 \%$ resistance, which was not explained well, was observed in study IV already prior to administering the phages. Post administration resistance in this study doubled and reached 13\%. Study V reported no effect of phages in 2 out of the 3 experimental groups, which could be due to resistance or because of the use of strain NCTC 12662 instead of a local C. jejuni isolate for demonstration of efficacy. Moreover, while the second study reported that the resistant strains were compromised in their ability to colonize chickens, rapidly reverting to the phage sensitive form, study IV did not observe this phenomenon, while study $\mathrm{V}$ identified multiple biotypes of $C$. jejuni in all three experimental sites. At the same time, all five studies reported the use of phages of approximately the same genomic size and morphology, placing them into the Myoviridae family. From the genomic sizes of the phages reported by study IV, it can be understood that the phages belonged to group II, which tend to be mostly flagellotropic. This can also be deduced from the fact that the phages described in the publication were specific to both C. jejuni and C. coli. Study III reported the use of phages from both groups (II and III) and concluded that application of cocktails using phages from different groups can increase the potency of phage cocktails.

Regarding the use of $C$. jejuni strains for artificial infections, in the first three studies, the scientists used chickens experimentally infected with a single C. jejuni or C. coli strain. In reality, research 
suggests that multiple strains of this pathogen may be present even in a single individual bird. Still, the results demonstrated that the two phages of similar size from the same Myoviridae family may have quite different lytic profiles and efficacy. This supports evidence that local phage isolates could be more effective towards the host bacterial strains isolated in the same locality, although it is not clear whether the phage isolates in study II were not obtained as a result of selection using C. jejuni strain NCTC 12662. The two phages clearly exhibited different efficacy profiles towards the two bacterial hosts, C. jejuni HPC5 and C. jejuni GIIC8, and were used as single agents. Administered as a cocktail, these phages could demonstrate improved efficacy against a single host as well as against a combination of the two hosts used.

Overall, the results from all the five in vivo studies agree that phages can effectively reduce C. jejuni if administered 24-48 h prior to slaughter at high M.O.I. experimentally established prior to administering. Efficacy of phage applications may be improved if local isolates of both bacteriophages and putative hosts are used. Further studies are needed to substantiate these findings and to achieve reduction of $C$. jejuni exceeding $2 \log _{10}$ levels, which, according to the authors of studies II and IV and based on mathematical models, can be translated into an approximately 30 -fold reduction of the pathogen. This, however, is not nearly enough to achieve sustainable public benefit. Therefore, further research should probably focus on using cocktails consisting of both CPS-specific (group III) and flagellotropic (group II) phages applied as a cocktail with carefully planned stability experiments, proving that phage preparations can withstand the conditions of the selected route of administration, as well as that of a buffer or carrier substance.

\subsection{In Situ Testing}

Five research teams addressed the question of whether application of phages at refrigerated temperatures could be effective against $C$. jejuni.

Reduction of this pathogen was demonstrated by two different groups-Atterbury et al. (study I) and Goode et al. (study II) [15,65]—on artificially contaminated skin following treatment with high titers of group III lytic phages.

Orquera et al. (study III), who also used group II phages in their research, concluded that the latter were unable to reduce $C$. jejuni in situ at $4{ }^{\circ} \mathrm{C}$ [66]. Similar to studies I and II, Orquera and colleagues obtained the phages (CP81 and NCTC 12684) and the host bacterial strains (C. jejuni NCTC 11168 and C. coli NCTC 12668) from bio banks. The experiments were conducted at $37^{\circ} \mathrm{C}$ in broth, as well as at $4{ }^{\circ} \mathrm{C}$ on meat. While $1-2 \log _{10}$ levels reduction was achieved in broth, no significant change in the numbers of C. jejuni was reported at $4{ }^{\circ} \mathrm{C}$ on meat. In contrast, phages against $Y$. enterocolitica were able to reduce the host bacteria up to $2 \log _{10}$ levels at the same temperature on meat in the same study. These results are consistent with the evidence that $C$. jejuni may remain viable at $4{ }^{\circ} \mathrm{C}$, although it cannot multiply at this temperature. This could be the reason why phage treatments are less effective at refrigerated temperatures.

The conclusions from studies I and II also contradict those of Firlieyanti et al. (study IV) and Zampara et al. (study V). In their experiments, the latter two teams used either group II flagellotropic phages or phage preparations consisting of group II and group III bacteriophages. Reduction of C. jejuni at low temperatures in these studies was found to be modest due to poor efficacy of group II flagellotropic phages at such temperatures, according to the authors of the published results [27,67].

As mentioned earlier, in studies I-III the host bacteria and their bacteriophages were obtained from bio banks and were not isolated from any specific locality. For example, C. jejuni NCTC 12662 and C. jejuni C222 were used as the host strains in studies I and II, respectively. These studies, therefore, cannot represent a realistic scenario where various types of host bacteria and their phages exist. Nevertheless, they provided valuable information that, if applied at high titers, some phages are indeed able to significantly reduce $C$. jejuni in situ. The success of the first study, however, could be explained by the fact that C. jejuni NCTC 12662 is readily infected with phages and, for this reason, is 
often used for selection of bacteriophages. That is obviously why study IV used this strain for phage propagation purposes.

Study IV used the isolates of the host bacterial strains and their phages from the same local source (specifically, chicken livers). The results, as seen in Table 2, were modest. It could be argued that studies I and II were more successful in reduction of $C$. jejuni because both teams used group III lytic phages. However, phage CP81 used in the study III was also a group III phage, but inefficient with the particular strain of $C$. jejuni (NCTC 11162). Indeed, this strain could be less susceptible to phages compared to C. jejuni NCTC 11162 used in previous research. Thus, wherever group III phages were utilized in studies III and IV, the low rate of clearance of $C$. jejuni can be explained because the efficacy studies were conducted using host strains other than NCTC 12662.

Study IV effectively demonstrated that $C$. jejuni could remain viable at $4{ }^{\circ} \mathrm{C}$ during a $72 \mathrm{~h}$ period, which is critical for phage survival. Viability was confirmed by unchanged levels of phage recovery from such samples. However, because the pathogen does not actively divide at such low temperatures, phages also remain static. Another important observation of study IV was that flagellotropic phages $\Phi 3$ and $\Phi 15$ were able to lyse three out of five chicken liver isolates of $C$. jejuni in addition to the control strain HPC5. This indicates that the outcome of phage treatments could be largely dependent upon the origin of both bacteriophages and the host bacteria.

Study V conducted by Zampara and colleagues investigated the efficacy of 19 Campylobacter phages isolated locally throughout chicken farms in Denmark and used two C. jejuni strains, NCTC 12662 and RM1221. In particular, since previous research focused mostly on group III bacteriophages, this team also included group II (mostly flagellotropic) phages in their experiments and found significant difference between the ability of group III and group II phages to reduce C. jejuni loads. Specifically, group III phages led to $0.55 \log _{10}$ level reduction at $4{ }^{\circ} \mathrm{C}$ on chicken skin, while no reduction was achieved by group II phages. To answer the question of whether decreased motility could be the reason for the low efficacy displayed by flagellotropic phages, the RM1221 strain was also used as a control. This C. jejuni strain is characterized by enhanced motility. Decreased motility of NCTC 12662 at $4{ }^{\circ} \mathrm{C}$ was not observed. Therefore, the inefficiency of group II phages could not be explained by decreased motility of the host bacteria. The noteworthy observation of study $\mathrm{V}$ was that, despite the use of NCTC 12662 (the strain that is readily infected with most phages), significantly lower efficacy results were obtained with group III phages in this study.

As was the case with the in vivo research discussed above, the five in situ studies evolved sequentially. The first two studies introduced the idea of phage application at refrigerated temperatures, while the subsequent investigations tried to answer more specific questions or confirm the findings of the previous research. Thus, studies IV and V evolved into more thorough investigations utilizing a more diverse population of phages. Future research, therefore, should probably narrow down on specific phage isolates and screen those against multiple isolates of $C$. jejuni. However, both should come from the same source of meats and chicken excreta. Again, cocktails consisting of different phage isolates should be used. This time more pertinent questions must be answered, such as: could in vivo treatment be complemented by in situ treatment of the same chicken meat post slaughter with the same, or different, phages or phage cocktails?

\section{The Future of Campylophages: Improving Selection and Handling Resistance}

\subsection{Improving Phage Selection}

An improved method of isolation of Campylobacter phages was suggested by An-Chi Tsuei and colleagues by pooling the parts of the whole chicken rinses. The method allowed for $28 \%$ recovery of $C$. jejuni phages [68]. This approach is consistent with the isolation of $C$. jejuni from retail chicken by rinsing bird carcasses with buffered peptone water [69]. Phage isolation, however does not pose a major problem. What needs to be addressed in research studies is using local isolates of $C$. jejuni for selection of phages to increase their diversity. For example, for enrichment of phage isolates, 
Furuta et al., who found that phage susceptibility profiles of the Japanese Campylobacter strains were different from those of non-Japanese ones, suggest using locally isolated $C$. jejuni strains [70]. Previous research of Campylobacter phages relied heavily on just a few C. jejuni strains, notably NCTC 12662, which was frequently used for propagation and enrichment of phages, as discussed previously in this work. However, it is essential to use a broad range of strains for the selection and isolation of Campylobacter phages, because the primary phage isolation strain largely determines both phage type (CP81 or CP220) and receptors (CPS or flagella), as demonstrated by Sørensen and colleagues [40]. The use of control C. jejuni strains, also known as phage propagating strains (NCTC 12662 (PT14), NCTC 12660, NCTC 12661 and NCTC 12664), susceptible to a wide range of phages may have resulted in biased selection of the latter [37,71]. For example, Sørensen and colleagues used C. jejuni strains with different CPS profiles to isolate bacteriophages from free-range poultry samples. All 20 phage isolates were obtained using C. jejuni NCTC 12658, NCTC 12662 and RM1221. The phage isolates were subject to host range and genome restriction profile determination analysis concluding that the host range and morphology of the isolated phages correlated with the bacterial strains used for isolation. Thus, NCTC 12662 allowed for the isolation of CP81-type phages, while RM1221 determined CP220-type selection, as shown by phage specificity studies using either acapsular or non-motile mutants [72]. Thus, to diversify a phage collection, local strains of $C$. jejuni must be isolated and characterized first.

\subsection{Understanding and Handling Phage Resistance in C. jejuni}

Bacterial resistance to phages was first noted by d'Herelle [45]. Later Delbrück and Luria also observed that initial lysis of bacteria resulted in subsequent re-growth [73]. Today it is widely known that resistance of bacterial strains to bacteriophages can be a major drawback in the development of therapeutic phage applications. There is also some concern that development of phage resistant bacterial strains could lead to limited long-term sustainability of phage applications, as it is the case now with antibiotic drugs [74]. Resistance of $C$. jejuni to their bacteriophages is making the wider use of the latter challenging. Development of phage resistance was noted in most Campylobacter studies, both in vivo and in vitro. For example, in their 2005 in vivo study Loc Carrillo and colleagues identified $4 \%$ and $11 \%$ resistant isolates of $C$. jejuni HPC5 [2]. The majority of these resistant isolates (97\%) reverted back to the phage sensitive phenotype when tested again later, as confirmed by MLST analysis [2]. Notably, this study also showed that different phages of the same group (lytic group III phages) can elicit different levels of resistance in the host bacterial strain. Thus, phage CP8 was more effective in infecting and reducing HPC5 compared to phage CP34 and with the majority of $C$. jejuni subpopulations remaining phage-sensitive. The ability of phage resistant subpopulations of $C$. jejuni to revert back to phage-sensitive form was further observed by Carvalho and colleagues, who noted that colonization of chicken gut was possible via quick reversion of the resistant phenotype of $C$. jejuni to the original parental phenotype [63].

Analysis of previous research identified at least three distinct mechanisms of phage resistance in C. jejuni. Additionally, all bacteria have restriction modification systems to recognize and neutralize foreign DNA. The mechanisms of bacterial resistance to bacteriophage infection are as follows:

(a) Receptor modification preventing phage adsorption

(b) Diversity of $C$. jejuni strains

(c) Resistance due to spontaneous mutations

(d) Intracellular degradation of phage DNA

(e) CRISPR-Cas system mediated bacterial dormancy

\subsubsection{Receptor Modification Preventing Phage Adsorption}

Receptor modification is the most common mechanism of resistance to phages in bacteria. Such modifications may arise due to point mutations of receptor-encoding genes or result from changes in their expression [33]. 
Recently, the phase variable O-methyl phosphoramidate (MeOPN) moiety of the CPS has been shown to be the determinant of the resistance in C. jejuni NCTC 11168R. Experiments revealed that resistance can be acquired in vivo and a particular strain can transfer cross-resistance to other phages. Thus, phase variable CPS structures are able to modulate phage infectivity of $C$. jejuni. Changes in these structures arise in response to the constant exposure to phages in the chicken gut resulting in continuous and dynamic phage-host co-evolution [42,72].

In the context of group II flagellotropic phages, mutation of flagellar receptors could also play a role in phage resistance. That is what Lis and Connerton reported in their study of a flaB knockout strain of $C$. jejuni PT14. According to their research, flaB inactivation led to a decrease in swarming motility of bacterial cells and increased their susceptibility of this strain to phage CP_F1. Thus, maintenance of flaB gene, according to this study, could be an evolutionary adaptation towards increasing the diversity of antigens in order to evade infection from flagellotropic phages [75].

\subsubsection{Diversity of $C$. jejuni Strains}

The extreme diversity of $C$. jejuni strains is one of the causes of development of resistance. Research showed that several C. jejuni strains may coexist in one broiler flock at any given time $[21,63,64]$. Co-existence of strains with different phage susceptibilities in broiler flocks was observed by other authors and explains the finding of Scott et al. and Connerton et al. that succession of C. jejuni strains during phage application occurs due to new genotypes instead of the existing strains becoming resistant $[76,77]$. The reason why $C$. jejuni $C F U$ counts rise again after the initial reduction post phage application is most probably caused by the susceptible strains giving way to non-susceptible ones. For example, the diversity of $C$. jejuni strains was confirmed by Kittler and colleagues by the use of MLST analysis to characterize $C$. jejuni isolates from three different farms. They identified two sequence types (STs) in each of the two different experimental groups. The sequence types and phage susceptibility did not coincide from group to group. Moreover, in two out of four total possible biotypes determined among the isolates, these different biotypes sometimes belonged to one sequence type, thus making the results between the three trials highly variable. For example, in trial 3 , the susceptibility and biotype matched, while in trial 1 reduction took place in vivo, despite no susceptibility being shown in vitro [64]. Previous studies also observed that in vitro and in vivo data may differ substantially, resulting from different genetic variants of Campylobacter in different flocks [78].

\subsubsection{Resistance Due to Spontaneous Mutations}

Phage-resistant bacterial strains sometimes arise due to spontaneous mutations. Once a bacteriophage threat is eliminated, bacteria revert to a phage-sensitive strain [35]. Loc Carrillo et al. and Scott et al. showed that phage resistant isolates may arise due to chromosomal inversion and that resistant strains exhibit decreased ability to colonize birds [2,77]. In fact, phage-susceptible $C$. jejuni subpopulations can overgrow phage resistant populations due to increased motility, as shown by Kittler et al., although only in vitro [64]. Brathwaite and colleagues, also noticed the decreased ability of biofilm-associated $C$. jejuni subpopulation, infected with lytic phages in CSLC, to colonize broilers. RNA-seq analysis found that the decreased fitness was due to down-regulation of important stress-response genes, including the major flagellar protein FlaA [79]. The conclusion drawn from these observations is that, due to the short lifespan of broilers, it is unclear how the dynamics of resistance continue.

\subsubsection{Intracellular Degradation of Phage DNA}

Another aspect that has been barely studied so far in the context of phages is the intercellular degradation of extraneous DNA depending on its methylation pattern by restriction modification systems (RM-systems). RM-systems principally consist of three types of subunits: (i) restriction endonuclease subunits (R) facilitating DNA cleavage, (ii) specificity subunits (S) for the detection of specific DNA sequence motifs, and (iii) DNA methylase subunits (M) [80]. A highly conserved 
methylase that recognizes and methylates the RA ${ }^{\mathrm{m} 6}$ ATTY motif [80] was identified, which significantly increases the transformation rate and was therefore named Campylobacter transformation system methyltransferase (ctsM) [81]. In turn, reduced RA ${ }^{\mathrm{m} 6}$ ATTY motif methylation leads to increased degradation by methylation-associated RM systems that degrade DNA lacking the correct methylation motif. Consequently, phage resistance may also be due to reduced methylation of specific motifs of phage DNA.

\subsubsection{CRISPR-Cas System Mediated Bacterial Dormancy}

The innate immunity of bacteria against phages is represented by CRISPR-Cas systems that have been classified into two classes, 6 types, and more than 30 subtypes. Recently it has been observed that, unlike the type I CRISPR-Cas system, which constitutes about $60 \%$ of all CRISPR-Cas systems, types III and VI can induce cell dormancy and thus decrease an infected population of cells. It is also thought that the type V CRISPR-Cas system may actually lead to cell death [82].

Watson et al. demonstrated in their study that infection of Pectobacterium atrosepticum by two independent phages, $\Phi T E$ and $\Phi M 1$, activates type I CRISPR immunity. This results in abortive infection and leads to death of infected cells. Therewith the phage propagation was decreased. Thus CRISPR-Cas type I systems may serve as tool to reduce phage infection and protect given bacterial populations from infection [82].

\subsubsection{Handling Resistance}

Two possible solutions exist to control resistance to phages in farm environments. The first is to apply phages strictly for 24 to $48 \mathrm{~h}$ to birds designated for slaughter after physical sequestration in order to prevent the spread of the infection to other birds. The in vivo studies discussed earlier identified that the efficacy of the high titer phage applications can be observed within $48 \mathrm{~h}$, after which it either drops entirely or is maintained at a lower level. Therefore, application of phages towards the end of a production cycle (before slaughter and possibly on carcasses) could alleviate selective pressure on the pathogen.

Another solution is modification of phage products. As mentioned earlier, using phage cocktails consisting of two or more phages, preferably from different groups, is more effective than monophage applications. Hammerl and colleagues were able to demonstrate this in using group III and group II phages in a pre-harvest treatment showing reduction up to $3 \log _{10}$ levels of fecal counts of Campylobacter in 20-day-old chickens administered successively with the two phages.. While the group III phage alone was not effective, a combination of the two (group II and III) proved to be efficient [83]. The advantage of using applications consisting of multiple phages is that bacterial resistance comes at a certain fitness cost. Such a fitness cost can be maximized by simultaneous pressure from multiphage applications. In response, the pressure exerted on bacteria from combinations of phages would have to be met with multiple mutations in a given bacterial cell, which means that resistant bacteria would possess less cellular fitness and could eventually be outgrown by a non-resistant phenotype [74]. This was exactly the case with resistant $C$. jejuni phenotypes in some studies discussed earlier. Finally, avoiding application of monophages decreases development of cross-resistance when, for example, different phages may target the same bacterial surface receptor. The efficacy of bacteriophage cocktails, thus, could be increased by alternation. Additionally, specific phages within cocktails could be replaced with new characterized phages from an existing library or with new phage isolates from the environment. In any case, preventing resistance requires constant surveillance and obtaining new phage isolates. This makes isolation and characterization of wild type phages extremely important in an effort to obtain potent isolates and prevent emergence of phage resistant phenotypes.

Additionally, the third effective route to control phage resistance in bacteria could be genetic modification of existing phages. However, the regulatory path of such phage preparations is presently unclear. 


\section{Determining Safety of Phages in the Era of "Omics"}

Despite the fact that bacteriophages are the most ubiquitous organisms inhabiting every niche of the biosphere, there is still an incredible lack of both genotypic and phenotypic information about these viruses largely due to traditional culture-based approach of their identification. However, recent rapid advances in sequencing technologies have revolutionized the ability to produce high-throughput sequencing data of whole bacterial and viral genomes without the need for their prior isolation, as in the technique of metagenomics. At the same time, the cost of sequencing has decreased considerably. Metagenomics (genomic analysis of a pool or a community of organisms), single cell genomics (analysis of the genome of a single cell) and other "omics" technologies, together with bioinformatics and statistical analysis tools, have created a powerful basis for the analysis of large sequencing datasets and shed light on bacteriophages and their interaction with their host bacteria.

There are several high throughput whole genome sequencing technologies available today, each with their own advantages and disadvantages, such as the read length and the sequencing error rate. Hybrid sequencing can be used in cases where low error rate and large read length are required [84]. Bioinformatics tools available for the assembly, mapping and identification of bacteriophage genomes from the perspective of determining their safety and thus applicability in human or animal therapy have, consequently, been evolving rapidly.

Although phages are generally considered safe, the need for guidelines and methods to assure the safety of their genomes still exists. Lysogenic phages often carry undesirable genes that could be detrimental to the bacterial host, upon expression of virulence factors, or proteins able to degrade various antibiotics. Therefore, guidelines are needed to analyze and differentiate phages designated for therapy in humans or animals by their lifecycle. Such guidelines do not yet exist [85]. The US FDA, for example, relies on emergency protocols proposed by medical doctors for the case-by-case approval of phage cocktails for therapeutic purposes in special "compassionate" use of Investigational New Drugs (IDEs). Recently, a team of scientists from United States Defense Threat Reduction Agency and Biological Defense Research Directorate, Naval Medical Research Center developed a comprehensive workflow to assess the genomic safety of therapeutic bacteriophages [85]. The checkpoints in the proposed assessment include obtaining high quality genomic sequencing data and rigorous analysis of this data to identify sequencing contamination and evaluate safety. The effectiveness of this assessment pipeline has been demonstrated on the bases of two phage genomes and has been proposed by the group as the minimum standard for evaluating the safety of phages. The workflow of data analysis follows these three essential steps: analysis of data quality, determining the lifecycle, and analysis of the proteome. All three stages rely on bioinformatics tools and statistical software for data analysis [85].

The first stage of the safety assessment is data quality: there are several bioinformatics pipelines to evaluate the quality of sequencing data and at least two should be employed in parallel for data QC (quality check) and sequence alignment, including the manual verification of sequence fidelity and definition of the requirements for minimum coverage (in the range from $100 \times$ to $400 \times$ ) of the complete genome. Once this checkpoint is satisfied, the sequence must be mapped to the reference sequence. Again, at this stage, stringency must be defined as $90 \%$ or higher if the data can be mapped back to the original genome. The next step is determining the phage lifestyle, i.e., whether a particular phage sequence contains data that could implicate it as having a lysogenic lifestyle. Again, there are bioinformatics options (for example RAST and PHASTER) that can interrogate sequence for the presence of integrase. Presence of the latter, as well as positive prediction of lysogenicity of the proteome of a particular phage (e.g., by the additional bioinformatics tool PHACTS that is based on statistical analysis of the data) will disqualify it from further consideration. Likewise, presence of undesirable elements such as toxins, antibiotic resistance genes and virulence factors may also be checked with bioinformatics tools (for example, ShortBRED can read the sequence in question against databases ARDB and VFDB). Open reading frames can be assessed with tools such as Prodigal and others for homology of predicted ORFs with known proteins existing in various databases by BLASTp, PhAnTOME and other bioinformatics computational methods. The threshold for putative harmful 
genes could be set to $30 \%$ (which is quite low), as opposed to $50-70 \%$ for other homologs. Passing all these stringent checkpoints qualifies the phage for potential therapeutic use.

An alternative bioinformatics tool is PhagePhisher, which was developed in Loyola University Chicago and was designed to extract meaningful information from large sequencing datasets [86]. This pipeline processes viral-specific sequences from WGS data based on algorithms that identify non-viral elements by reassembling sequencing data to identify the viruses of interest. Such data can be extracted from sequences of single isolates or complex microbial communities. PhagePhisher was written in python and also encompasses a three-step process: identifying and processing contaminant or host species sequences (referred to as "background genome") with an option to mask prophage sequences, mapping the viral WGS reads to the background genome, and downstream analysis of those specific reads unable to map to the background, i.e., dissimilar elements. The advantage of this program is that it can work with essentially any mapping or assembly platforms. PhagePhisher was successfully used to identify the $P$. aeruginosa phage ( $\varphi$ Vader) genome by excluding annotated bacteriophage coding regions from host-derived sequences separated from those of the phage genome ( $69 \%$ of almost a 3 million base pair sequence). The remaining paired-end reads were assembled into the viral genome. Similar to the method discussed above, lysogenic phages can be identified by finding virus-like particles within bacterial genomic sequences because PhagePhisher is able to separate viral elements from bacterial sequences. This approach allowed one to analyze the raw sequencing paired end reads of a WGS survey of the nearshorewaters of Lake Michigan against all publicly available databases of bacterial genomes and plasmids. The paired-end reads were analyzed individually and the ones that mapped to the background were removed, while unmapped reads were then assembled separately. After subsequently BLASTing the five contigs against the $\mathrm{nr} / \mathrm{nt}$ database without preselecting any particular organism or taxa, all five produced statistically significant hits to various phage sequences. Additionally, by referencing the annotation of the cyanophage genome, one contig was found to be homologous to the phage's annotated integrase. At the same time, none of the identified contigs showed any homology with bacterial sequences, which proves that this screening can be effectively validated into guidelines for isolation of viral sequences.

There are other similar bioinformatics tools designed to check the quality of phage DNA (identifying potential contamination by host genome), analyze the sequencing results further to determine the lifestyle, and analyze the viral ORFs, for example, CyVerse in the PCPipe available through iVirus project. Besides PHAST, there are ACCLAIM, Prophinder and PhiSpy, which are also available as tools for prophage detection [87].

Finally, SSG (single cell genome) sequencing must be mentioned as a new tool for sequencing single bacterial cells shedding information on prophages contained in the bacterial genome and, in general, on the complex phage-host relationship. Single cells can be isolated by various technologies, such as FACS or confocal laser scanning microscopy. Alongside this, bioinformatics tools also evolve to accommodate these technologies with subsequent analysis, for example, PIPS, a method of classification of prophages-pathogenicity islands [87]. Thus, guidelines for characterizing phages to qualify them for therapeutic use will have to rely on complex methodologies and the validation of these guidelines will most likely be a complex, multi-step process.

\section{Concluding Remarks}

It is obvious that much work needs to be done to achieve significant and consistent reduction of $C$. jejuni at different stages of broiler production. Previously, it was shown using quantitative risk assessment modeling that a $2 \log _{10}$ level reduction of $C$. jejuni in broilers prior to slaughter would significantly decrease the incidence of campylobacteriosis in humans [61]. Application of polyvalent phage preparation is clearly one way to overcome phage resistance, at least partially. Such applications have a successful history of use, for example against Salmonella. Phage cocktail treatment significantly reduced this pathogen in ileum and cecal tonsils of chickens [30]. 
For wider activity and greater potency against C. jejuni, it is advisable that polyphage applications (phage cocktails) targeting this pathogen be comprised of the representatives of both CPS-specific and flagellotropic phages or to administer the phages from these groups successively [37,88]. Prevention of recycling of phages reduces resistance rates in a farm environment, therefore conducting phage therapy in birds 1-2 days prior to slaughter could help to avoid resistance [15].

As a final note, due to the ubiquitous presence of $C$. jejuni in the environment, successful elimination of this pathogen will most probably be achieved by implementing strict biosecurity measures complexed with phage treatments and probiotic supplements, making continued research in all areas necessary and relevant. This is especially true for Campylobacter phages. Characterizing and sequencing new $C$. jejuni phage isolates is much needed to gain more knowledge about these viruses.

Author Contributions: The idea for the paper was conceived by all authors. L.U., B.L., I.J., and A.E.Z. wrote, reviewed and edited the manuscript. Both L.U. and A.E.Z. supervised the final version of the manuscript. All authors have read and agreed to the published version of the manuscript.

Funding: The research of the authors was funded by the Deutsche Forschungsgemeinschaft (grant number ZA 697/6-1) as well as by the Shota Rustaveli National Science Foundation (SRNSF) and the Volkswagenstiftung under the collaborative project, Sustainable Agricultural and Food Systems (SAFS), between the University of Kassel, Germany, the University of Göttingen, Germany, and the Agricultural University of Georgia.

Conflicts of Interest: The authors declare no conflict of interest.

\section{References}

1. Ushanov, L. Reduction of C. jejuni may require complex approach. Ann. Agrar. Sci. 2018, 422-426. [CrossRef]

2. Loc Carrillo, C.; Atterbury, R.J.; Dillon, E.; Scott, A.; Connerton, I.F.; Connerton, P.L. Bacteriophage Therapy To Reduce Campylobacter jejuni Colonization of Broiler Chickens. Appl. Environ. Microbiol. 2005, 71, 6554-6563. [CrossRef]

3. Dasti, J.I.; Tareen, A.M.; Lugert, R.; Zautner, A.E.; Groß, U. Campylobacter jejuni: A brief overview on pathogenicity-associated factors and disease-mediating mechanisms. Int. J. Med. Microbiol. 2010, 300, 205-211. [CrossRef] [PubMed]

4. Mundi, A.; Declenserie, V.; Amiri-Jami, M.; Moorhead, S.; Griffiths, M.W. Cell-Free Preparations of Lactobacillus acidophilus Strain La-5 and Bifidobacterium longum Strain NCC2705 Affect Virulence Gene Expression in Campylobacter jejuni. J. Food Prot. 2013, 76, 1740-1746. [CrossRef] [PubMed]

5. Skarp, C.P.A.; Hänninen, M.L.; Rautelin, H.I.K. Campylobacteriosis: The role of poultry meat. Clin. Microbiol. Infect. 2016, 22, 103-109. [CrossRef] [PubMed]

6. Zautner, A.E.; Johann, C.; Strubel, A.; Busse, C.; Tareen, A.M.; Masanta, W.O.; Lugert, R.; Schmidt-Ott, R.; Groß, U. Seroprevalence of campylobacteriosis and relevant post-infectious sequelae. Eur. J. Clin. Microbiol. Infect. Dis. 2014, 33, 1019-1027. [CrossRef] [PubMed]

7. Alter, T.; Bereswill, S.; Glünder, G.; Haag, L.-M.; Hänel, I.; Heimesaat, M.M.; Lugert, R.; Rautenschlein, S.; Weber, R.M.; Zautner, A.E.; et al. Die Campylobacteriose des Menschen. Bundesgesundh. Gesundh. Gesundh. 2011, 54, 728-734. [CrossRef]

8. Roasto, M.; Praakle, K.; Korkeala, H.; Elias, P.; Hänninen, M.L. Prevalence of Campylobacter in raw chicken meat of estonian origin. VTT Symp Valt. Tek Tutk. 2008, 53, 61.

9. $\quad$ Epps, S.V.R.; Harvey, R.B.; Hume, M.E.; Phillips, T.D.; Anderson, R.C.; Nisbet, D.J. Foodborne Campylobacter: Infections, metabolism, pathogenesis and reservoirs. Int. J. Environ. Res. Public Health 2013, 10, 6292-6304. [CrossRef]

10. Thibodeau, A.; Fravalo, P.; Taboada, E.N.; Laurent-Lewandowski, S.; Guévremont, E.; Quessy, S.; Letellier, A. Extensive characterization of Campylobacter jejuni chicken isolates to uncover genes involved in the ability to compete for gut colonization. BMC Microbiol. 2015, 15, 97. [CrossRef]

11. Davis, M.A.; Conner, D.E. Survival of Campylobacter jejuni on poultry skin and meat at varying temperatures. Poult. Sci. 2007, 86, 765-767. [CrossRef]

12. Gomes, F.R.; Curcio, B.R.; Ladeira, S.R.L.; Fernández, H.; Meireles, M.C.A. Campylobacter jejuni occurrence in chicken fecal samples from small properties in Pelotas, Southern of Brazil. Braz. J. Microbiol. 2006, 37, 375-378. [CrossRef] 
13. Hwang, S.; Yun, J.; Kim, K.P.; Heu, S.; Lee, S.; Ryu, S. Isolation and characterization of bacteriophages specific for Campylobacter jejuni. Microbiol. Immunol. 2009, 53, 559-566. [CrossRef]

14. Pedonese, F.; Nuvoloni, R.; Turchi, B.; Torracca, B.; Di Giannatale, E.; Marotta, F.; Cerri, D. Prevalence, phenotypic and genetic diversity of Campylobacter in poultry fresh meat and poultry products on retail sale in Tuscany (Italy). Vet. Ital. 2017, 53, 29-37.

15. Goode, D.; Allen, V.M.; Barrow, P.A. Reduction of experimental Salmonella and Campylobacter contamination of chicken skin by application of lytic bacteriophages. Appl. Environ. Microbiol. 2003, 69, 5032-5036. [CrossRef] [PubMed]

16. EFSA. The European Union summary report on trends and sources of zoonoses, zoonotic agents and food-borne outbreaks in 2015. EFSA J. 2016, 14, 1-231.

17. EFSA. Scientific Opinion on Campylobacter in broiler meat production: Control options and performance objectives and/or targets at different stages of the food chain. EFSA J. 2011, 9, 1-141.

18. European Food Safety Authority and European Centre for Disease Prevention and Control (EFSA and ECDC). The European Union One Health 2018 Zoonoses Report. EFSA J. 2019, 17, 7-276.

19. Bishop-Hurley, S.L.; Rea, P.J.; McSweeney, C.S. Phage-displayed peptides selected for binding to Campylobacter jejuni are antimicrobial. Protein Eng. Des. Sel. 2010, 23, 751-757. [CrossRef] [PubMed]

20. Marotta, F.; Garofolo, G.; Di Donato, G.; Aprea, G.; Platone, I.; Cianciavicchia, S.; Alessiani, A.; Di Giannatale, E. Population diversity of Campylobacter jejuni in poultry and its dynamic of contamination in chicken meat. BioMed Res. Int. 2015, 2015. [CrossRef] [PubMed]

21. Barton, M.D.; Heuzenroeder, M.W.; Owens, J. The Use of Bacteriophages to Control Campylobacter Jejuni from Chickens. Ph.D. Thesis, University of South Australia, Adelaide, Australia, 2011.

22. Chaveerach, P.; Lipman, L.J.A.; van Knapen, F. Antagonistic activities of several bacteria on in vitro growth of 10 strains of Campylobacter jejuni/coli. Int. J. Food Microbiol. 2004, 90, 43-50. [CrossRef]

23. Ghareeb, K.; Awad, W.A.; Mohnl, M.; Porta, R.; Biarnes, M.; Bohm, J.; Schatzmayr, G. Evaluating the efficacy of an avian-specific probiotic to reduce the colonization of Campylobacter jejuni in broiler chickens. Poult. Sci. 2012, 91, 1825-1832. [CrossRef] [PubMed]

24. Janez, N.; Loc Carrillo, C. Use of phages to control Campylobacter spp. J. Microbiol. Methods 2013, 95, 68-75. [CrossRef] [PubMed]

25. LeLièvre, V.; Besnard, A.; Schlusselhuber, M.; Desmasures, N.; Dalmasso, M. Phages for biocontrol in foods: What opportunities for Salmonella sp. control along the dairy food chain? Food Microbiol. 2019, 78, 89-98. [CrossRef] [PubMed]

26. Mahony, J.; McAuliffe, O.; Ross, R.P.; van Sinderen, D. Bacteriophages as biocontrol agents of food pathogens. Curr. Opin. Biotechnol. 2011, 22, 157-163. [CrossRef]

27. Zampara, A.; Sørensen, M.C.H.; Elsser-Gravesen, A.; Brøndsted, L. Significance of phage-host interactions for biocontrol of Campylobacter jejuni in food. Food Control 2017, 73, 1169-1175. [CrossRef]

28. Frost, J.A.; Kramer, J.M.; Gillanders, S.A. Phage typing of Campylobacter jejuni and Campylobacter coli and its use as an adjunct to serotyping. Epidemiol. Infect. 1999, 123, 47-55. [CrossRef]

29. Khakria, R.; Lior, H. Extended phage-typing scheme for Campylobacter jejuni and Campylobacter coli. Epidemiol. Infect. 1992, 108, 403-414. [CrossRef] [PubMed]

30. Sillankorva, S.M.; Oliveira, H.; Azeredo, J. Bacteriophages and Their Role in Food Safety. Int. J. Microbiol. 2012, 2012, 1-13. [CrossRef]

31. Bai, J.; Kim, Y.T.; Ryu, S.; Lee, J.H. Biocontrol and rapid detection of food-borne pathogens using bacteriophages and endolysins. Front. Microbiol. 2016, 7, 1-15. [CrossRef]

32. Connerton, P.L.; Timms, A.R.; Connerton, I.F. Campylobacter bacteriophages and bacteriophage therapy. J. Appl. Microbiol. 2011, 111, 255-265. [CrossRef] [PubMed]

33. Verheust, C.; Pauwels, K.; Mahillon, J.; Helinski, D.R.; Herman, P. Contained use of Bacteriophages: Risk Assessment and Biosafety Recommendations. Appl. Biosaf. 2010, 15, 32-44. [CrossRef]

34. Wittebole, X.; De Roock, S.; Opal, S.M. A historical overview of bacteriophage therapy as an alternative to antibiotics for the treatment of bacterial pathogens. Virulence 2014, 5, 209-218. [CrossRef] [PubMed]

35. Aprea, G.; Zocchi, L.; Di Fabio, M.; De Santis, S.; Prencipe, V.A.; Migliorati, G. The applications of bacteriophages and their lysins as biocontrol agents against the foodborne pathogens Listeria monocytogenes and Campylobacter: An updated look. Vet. Ital. 2018, 54, 311. 
36. Sails, A.D.; Wareing, D.R.; Bolton, F.J.; Fox, A.J.; Curry, A. Characterisation of 16 Campylobacter jejuni and C. coli typing bacteriophages. J. Med. Microbiol. 1998, 47, 123-128. [CrossRef] [PubMed]

37. Jäckel, C.; Hammerl, J.; Hertwig, S. Campylobacter Phage Isolation and Characterization: What We Have Learned So Far. Methods Protoc. 2019, 2, 18. [CrossRef]

38. Hammerl, J.A.; Jäckel, C.; Reetz, J.; Beck, S.; Alter, T.; Lurz, R.; Barretto, C.; Brüssow, H.; Hertwig, S. Campylobacter jejuni Group III Phage CP81 Contains Many T4-Like Genes without Belonging to the T4-Type Phage Group: Implications for the Evolution of T4 Phages. J. Virol. 2011, 85, 8597-8605. [CrossRef]

39. Javed, M.A.; Ackermann, H.W.; Azeredo, J.; Carvalho, C.M.; Connerton, I.; Evoy, S.; Hammerl, J.A.; Hertwig, S.; Lavigne, R.; Singh, A.; et al. A suggested classification for two groups of Campylobacter myoviruses. Arch. Virol. 2014, 159, 181-190. [CrossRef] [PubMed]

40. Sørensen, M.C.H.; Gencay, Y.E.; Birk, T.; Baldvinsson, S.B.; Jäckel, C.; Hammerl, J.A.; Vegge, C.S.; Neve, H.; Brøndsted, L. Primary isolation strain determines both phage type and receptors recognised by Campylobacter jejuni bacteriophages. PLoS ONE 2015, 10, e0116287. [CrossRef]

41. Eric, C. Keen A century of phage research: Bacteriophages and the shaping of modern biology. Bioessays 2015, 37, 6-9.

42. Sørensen, M.C.H.; van Alphen, L.B.; Fodor, C.; Crowley, S.M.; Christensen, B.B.; Szymanski, C.M.; Brøndsted, L. Phase Variable Expression of Capsular Polysaccharide Modifications Allows Campylobacter jejuni to Avoid Bacteriophage Infection in Chickens. Front. Cell. Infect. Microbiol. 2012, 2, 1-11. [CrossRef] [PubMed]

43. Sarhan, W.A.; Azzazy, H.M.E. Phage approved in food, why not as a therapeutic? Expert Rev. Anti-Infect. Ther. 2015, 13, 91-101. [CrossRef] [PubMed]

44. Myelnikov, D. An Alternative Cure: The Adoption and Survival of Bacteriophage Therapy in the USSR, 1922-1955. J. Hist. Med. Allied Sci. 2018, 73, 385-411. [CrossRef] [PubMed]

45. Maciejewska, B.; Olszak, T.; Drulis-Kawa, Z. Applications of bacteriophages versus phage enzymes to combat and cure bacterial infections: An ambitious and also a realistic application? Appl. Microbiol. Biotechnol. 2018, 102, 2563-2581. [CrossRef] [PubMed]

46. Chan, B.K.; Abedon, S.T.; Loc Carrillo, C. Phage cocktails and the future of phage therapy. Future Microbiol. 2013, 8, 769-783. [CrossRef] [PubMed]

47. Bachrach, G.; Leizerovici-Zigmond, M.; Zlotkin, A.; Naor, R.; Steinberg, D. Bacteriophage isolation from human saliva. Lett. Appl. Microbiol. 2003, 36, 50-53. [CrossRef] [PubMed]

48. Mukhopadhya, I.; Segal, J.P.; Carding, S.R.; Hart, A.L.; Hold, G.L. The gut virome: The 'missing link' between gut bacteria and host immunity? Ther. Adv. Gastroenterol. 2019, 12, 1-17. [CrossRef]

49. Bojanova, D.P.; Bordenstein, S.R. Fecal Transplants: What Is Being Transferred? PLoS Biol. 2016, 14, 1-12. [CrossRef]

50. Mosley, S.L. Framework for FDA's review of food additives, color additives, GRAS substances, and food contact substances. ACS Symp. Ser. 2014, 1162, 27-34.

51. Sprous, D.G.; Salemme, F.R. A comparison of the chemical properties of drugs and FEMA/FDA notified GRAS chemical compounds used in the food industry. Food Chem. Toxicol. 2007, 45, 1419-1427. [CrossRef]

52. Larowe, D.E.; Cappellen, P.V. Preparation Containing Five Bacterial Monophages Specific to Shigella spp. GRAS notice (GRN) No. 672 Intralytix GRAS Notification for ShigaShield ${ }^{T M}$; FDA: Washington, DC, USA, 2016; pp. 1-39.

53. Dewey-Mattia, D.; Kisselburgh, H.; Manikonda, K.; Silver, R.; Subramhanya, S.; Sundararaman, P.; Whitham, H.; Crowe, S. Surveillance for Foodborne Disease Outbreaks United States. Annu. Rep. 2018, 1-15.

54. CDC (Centers for Disease Control and Prevention). Annual Summaries of Foodborne Outbreaks. In Food Safety; Foodborne Outbreak Surveillance System; U.S. Department of Health and Human Services, CDC: Atlanta, GA, USA, 2016.

55. Fischetti, V.; Loomis, L.; Trudil, D. Use of Bacterial Phage Associated Lytic Enzymes to Prevent Food Poisoning. U.S. Patent Application No. 10/394,574 US20040213765A1, 28 October 2004.

56. Fischetti, V.; Loomis, L.; Trudil, D. The Use of Bacterial Phage Associated Lytic Enzymes to Prevent Food Poisoning. U.S. Patent Application No. 10/394,574 CA2427928A1, 27 December 2002.

57. Connerton, I. Disinfection of Foodstuffs. Patent WO, 23010, A2 CA002545018A, 17 March 2005.

58. Burnett, S.; Gutzmann, T.; Cords, B. Bacteriophage Treatment for Reducing and Preventing Bacterial Contamination. U.S. Patent No. 9,486,007 US20090246336A1, 1 October 2009. 
59. Ter Haar, R.; Leigh Farris, H. Bacteriophage Treated Food Products. U.S. Patent Application No. 13/557,828 US20140030382A1, 30 January 2014.

60. EFSA. 2016 Evaluation of the safety and efficacy of Listex ${ }^{\mathrm{TM}} \mathrm{P} 100$ for reduction of pathogens on different ready-to-eat (RTE) food products. EFSA J. 2016, 14, e04565.

61. Wagenaar, J.A.; Bergen, M.A.P.V.; Mueller, M.A.; Wassenaar, T.M.; Carlton, R.M. Phage therapy reduces Campylobacter jejuni colonization in broilers. Vet. Microbiol. 2005, 109, 275-283. [CrossRef] [PubMed]

62. El-Shibiny, A.; Scott, A.; Timms, A.; Metawea, Y.; Connerton, P.; Connerton, I. Application of a group II Campylobacter bacteriophage to reduce strains of Campylobacter jejuni and Campylobacter coli colonizing broiler chickens. J. Food Prot. 2009, 72, 733-740. [CrossRef] [PubMed]

63. Carvalho, C.M.; Gannon, B.W.; Halfhide, D.E.; Santos, S.B.; Hayes, C.M.; Roe, J.M.; Azeredo, J. The in vivo efficacy of two administration routes of a phage cocktail to reduce numbers of Campylobacter coli and Campylobacter jejuni in chickens. BMC Microbiol. 2010, 10, 232. [CrossRef] [PubMed]

64. Kittler, S.; Fischer, S.; Abdulmawjood, A. Effect of Bacteriophage Application on Campylobacter jejuni Loads in Commercial Broiler Flocks. Appl. Environ. Microbiol. 2013, 79, 7525-7533. [CrossRef] [PubMed]

65. Atterbury, R.J.; Connerton, P.L.; Dodd, C.E.R.; Rees, C.E.D.; Connerton, I.F. Isolation and characterization of Campylobacter bacteriophages from retail poultry. Appl. Environ. Microbiol. 2003, 69, 4511-4518. [CrossRef]

66. Orquera, S.; Gölz, G.; Hertwig, S. Control of Campylobacter spp. and Yersinia enterocolitica by virulent bacteriophages. J. Mol. Genet. Med. 2012, 6, 273-278. [CrossRef]

67. Firlieyanti, A.S.; Connerton, P.L.; Connerton, I.F. Campylobacters and their bacteriophages from chicken liver: The prospect for phage biocontrol. Int. J. Food Microbiol. 2016, 237, 121-127. [CrossRef]

68. Tsuei, A.C.; Carey-Smith, G.V.; Hudson, J.A.; Billington, C.; Heinemann, J.A. Prevalence and numbers of coliphages and Campylobacter jejuni bacteriophages in New Zealand foods. Int. J. Food Microbiol. 2007, 116, 121-125. [CrossRef]

69. Gharst, G.; Oyarzabal, O.A.; Hussain, S.K. Review of current methodologies to isolate and identify Campylobacter spp. from foods. J. Microbiol. Methods 2013, 95, 84-92. [CrossRef]

70. Furuta, M.; Nasu, T.; Umeki, K.; Hoang Minh, D.; Honjoh, K.-I.; Miyamoto, T. Characterization and Application of Lytic Bacteriophages against Campylobacter jejuni Isolated from Poultry in Japan. Biocontrol. Sci. 2017, 22, 213-221. [CrossRef] [PubMed]

71. Sacher, J.C.; Yee, E.; Szymanski, C.M.; Miller, W.G. Complete Genome Sequences of Three Campylobacter jejuni Phage-Propagating Strains. Genome Announc. 2018, 6, 1-2. [CrossRef] [PubMed]

72. Gencay, Y.E.; Sørensen, M.C.H.; Wenzel, C.Q.; Szymanski, C.M.; Brøndsted, L. Phase variable expression of a single phage receptor in Campylobacter jejuni NCTC12662 influences sensitivity toward several diverse CPS-dependent phages. Front. Microbiol. 2018, 9, 1-13. [CrossRef] [PubMed]

73. Oechslin, F. Resistance Development to Bacteriophages Occurring during Bacteriophage Therapy. Viruses 2018, 10, 351. [CrossRef]

74. Wright, R.C.T.; Friman, V.-P.; Smith, M.C.M.; Brockhurst, M.A. Resistance Evolution against Phage Combinations Depends on the Timing and Order of Exposure. MBio 2019, 10, e01652-19. [CrossRef]

75. Lis, L.; Connerton, I.F. The minor flagellin of Campylobacter jejuni (FlaB) confers defensive properties against bacteriophage infection. Front. Microbiol. 2016, 7, 1-12. [CrossRef]

76. Connerton, P.L.; Loc Carrillo, C.M.; Swift, C.; Dillon, E.; Scott, A.; Rees, C.E.D.; Dodd, C.E.R.; Frost, J.; Connerton, I.F. Longitudinal study of Campylobacter jejuni bacteriophages and their hosts from broiler chickens. Appl. Environ. Microbiol. 2004, 70, 3877-3883. [CrossRef]

77. Scott, A.E.; Timms, A.R.; Connerton, P.L.; El-Shibiny, A.; Connerton, I.F. Bacteriophage influence Campylobacter jejuni types populating broiler chickens. Environ. Microbiol. 2007, 9, 2341-2353. [CrossRef]

78. Klein, G.; Beckmann, L.; Vollmer, H.M.; Bartelt, E. Predominant strains of thermophilic Campylobacter spp. in a German poultry slaughterhouse. Int. J. Food Microbiol. 2007, 117, 324-328. [CrossRef]

79. Brathwaite, K.J.; Siringan, P.; Connerton, P.L.; Connerton, I.F. Host adaption to the bacteriophage carrier state of Campylobacter jejuni. Res. Microbiol. 2015, 166, 504-515. [CrossRef]

80. Zautner, A.E.; Goldschmidt, A.-M.; Thürmer, A.; Schuldes, J.; Bader, O.; Lugert, R.; Groß, U.; Stingl, K.; Salinas, G.; Lingner, T. SMRT sequencing of the Campylobacter coli BfR-CA-9557 genome sequence reveals unique methylation motifs. BMC Genom. 2015, 16, 1088. [CrossRef]

81. Beauchamp, J.M.; Leveque, R.M.; Dawid, S.; DiRita, V.J. Methylation-dependent DNA discrimination in natural transformation of Campylobacter jejuni. Proc. Natl. Acad. Sci. USA 2017, 114, E8053-E8061. [CrossRef] 
82. Watson, B.N.J.; Vercoe, R.B.; Salmond, G.P.C.; Westra, E.R.; Staals, R.H.J.; Fineran, P.C. Type I-F CRISPR-Cas resistance against virulent phages results in abortive infection and provides population-level immunity. Nat. Commun. 2019, 10, 1-8. [CrossRef]

83. Hammerl, J.A.; Jäckel, C.; Alter, T.; Janzcyk, P.; Stingl, K.; Knüver, M.T.; Hertwig, S. Reduction of Campylobacter jejuni in broiler chicken by successive application of group II and group III phages. PLoS ONE 2014, 9, e114785. [CrossRef]

84. De Maio, N.; Shaw, L.P.; Hubbard, A.; George, S.; Sanderson, N.; Swann, J.; Wick, R.; AbuOun, M.; Stubberfield, E.; Hoosdally, S.J.; et al. Comparison of long-read sequencing technologies in the hybrid assembly of complex bacterial genomes. Microb. Genom. 2019, 5, e000294. [CrossRef]

85. Philipson, C.; Voegtly, L.; Lueder, M.; Long, K.; Rice, G.; Frey, K.; Biswas, B.; Cer, R.; Hamilton, T.; Bishop-Lilly, K. Characterizing Phage Genomes for Therapeutic Applications. Viruses 2018, 10, 188. [CrossRef]

86. Hatzopoulos, T.; Watkins, S.C.; Putonti, C. PhagePhisher: A pipeline for the discovery of covert viral sequences in complex genomic datasets. Microb. Genom. 2016, 2, e000053. [CrossRef] [PubMed]

87. Parmar, K.M.; Gaikwad, S.L.; Dhakephalkar, P.K.; Kothari, R.; Singh, R.P. Intriguing Interaction of Bacteriophage-Host Association: An Understanding in the Era of Omics. Front. Microbiol. 2017, 8, 559. [CrossRef] [PubMed]

88. Richards, P.J.; Connerton, P.L.; Connerton, I.F. Phage Biocontrol of Campylobacter jejuni in Chickens Does Not Produce Collateral Effects on the Gut Microbiota. Front. Microbiol. 2019, 10, 1-10. [CrossRef] [PubMed]

(C) 2020 by the authors. Licensee MDPI, Basel, Switzerland. This article is an open access article distributed under the terms and conditions of the Creative Commons Attribution (CC BY) license (http://creativecommons.org/licenses/by/4.0/). 